\title{
Characterizing Carver and White's BIS/BAS subscales using the Five Factor Model of personality
}

Segarra, P., Poy, R., López, R., \& Moltó, J.

\begin{abstract}
This study examined BIS/BAS scales (Carver \& White, 1994) assessment of Gray's revised Reinforcement Sensitivity Theory in the light of the Five-Factor Model of personality assessed via NEO-PI-R domains and facets — in a mixed-gender sample of 329 undergraduates. Exploratory factor analysis confirmed a 5-factor solution structure of the BIS/BAS scales, with BIS-scale divided into BIS-Anxiety and BIS-Fear factors, besides the original three BAS factors. BIS-Anxiety was found to represent Gray's anxiety (high Neuroticism and low Extraversion), being also distinguished from BIS-Fear by high Agreeableness, as expected. Interestingly, Conscientiousness showed divergent relationships to BIS-Anxiety (+) and BIS-Fear (-) as well. It is noteworthy that Agreeableness and Conscientiousness also marked distinct facets of BAS-related activity: distinctions in terms of low vs. high Conscientiousness pointed to differential measure of sensation-seeking and impulsiveness (BAS-Fun Seeking) vs. reward-orientation in goal-directed behavior (BASReward Responsiveness, BAS-Drive), with low Agreeableness additionally emphasizing a competitive interpersonal style for approaching goals (BAS-Drive). Our findings suggest that BAS total scores could be obscuring differential associations at the subscales level, and encourage further research on personality traits underlying each component of BAS activation.
\end{abstract}


Keywords: Reinforcement Sensitivity Theory, Five Factor model of personality, BIS, BAS, NEO-PI-R, anxiety, fear

\section{Introduction}

Jeffrey A. Gray’s Reinforcement Sensitivity Theory (RST; Gray, 1970, 1982, 1987, 1991; Gray \& McNaughton, 2000) is now one of the most influential neuropsychological models of personality. In its original version, the RST encompassed three major brain systems underlying individual differences in behavior and personality in response to environmental stimuli. The Behavioral Approach System (BAS) was activated by conditioned appetitive stimuli (i.e., signals of reward or non-punishment), eliciting approach behavior toward desired goals. It was proposed as the basis of impulsivity, and was hypothesized to relate positively to Eysenck's Extraversion and Neuroticism. The Behavioral Inhibition System (BIS) was activated by conditioned aversive stimuli (i.e., signals of punishment or non-reward) and intense or novel/unexpected stimuli, resulting in the interruption of ongoing behavior and simultaneous direction of attention toward the potential threat. It was associated with the experience of anxiety and should be positively related to Eysenck's Neuroticism, but negatively to Extraversion. The Fight/Flight System (FFS) was activated by unconditioned aversive stimuli, provoking defensive aggression or escape behavior — and being related to the emotional states of rage and panic, and likely with Eysenck's trait of Psychoticism (Gray, 1981; see Heym \& Lawrence, 2010, for a revision of the role of Psychoticism in Gray's RST).

Gray and McNaughton (2000) updated RST in order to incorporate data from neurophysiological animal research of anxiety and studies designed to test RST in the human experimental laboratory (see Corr, 2004, 2008, for an extensive revision). In the revised model, the BAS remains mediating reactions to appetitive stimuli — but now including also unconditioned ones-, and is associated with extraversion, reward-orientation, and 
impulsiveness. Conversely, the FFS now mediates responses to both unconditioned and conditioned aversive stimuli and, importantly, it is now related to the emotion of fear, not anxiety. Finally, the BIS is turned into a conflict detection system, responsible for resolving all goal conflicts between reward and/or punishment contingencies. This generates the emotion of anxiety, which is subjectively experienced as worry and rumination (Gray \& McNaughton, 2000). Thus, revised RST highlighted the need to distinguish FFS and BIS at the level of personality so as to reflect the dissociation between fear and anxiety found at neurophysiological and behavioral levels (cf. Corr \& McNaughton, 2008), even though a general factor of Neuroticism likely relates to both systems (McNaughton \& Corr, 2004).

However, it is unclear how self-report questionnaires developed to measure personality such as conceptualized in Gray's original RST can tap individual differences in anxiety and fear now underlying the new BIS and FFS systems, respectively. Concerning this, Corr and McNaughton (2008) suggested that anxiety and fear could be distinguished within the existing BIS-scale of one of the most widely used measures of original RST, the Carver and White's (1994) BIS/BAS scales. In fact, Johnson, Turner, and Iwata (2003) identified two items of the BIS-scale — which explicitly mention the word "fear"- loading on a separate factor from the other items, and, later, Heym, Ferguson, and Lawrence (2008) suggested the inclusion of a third item. The remaining four-items of the BIS-scale, which content captures the notion of worry about making mistakes or social comparison, are instead related to the emotion of anxiety (see Smillie, Pickering, \& Jackson, 2006). The first systematic studies testing the structure of the BIS-scale have supported both the two- (e.g., Beck, Smits, Claes, Vandereycken, \& Bijttebier, 2009; Poythress, Skeem, Weir, Lilienfeld, Douglas, Edens, \& Kennealy, 2008) and the three-item BIS-Fear scale solution (e.g., Dissabandara, Loxton, Dias, Daglish, \& Stadlin, 2012; Heym et al., 2008). These mixed findings have been attributed to 
differences in the samples used —offenders and clinical patients vs. undergraduates, respectively (Dissabandara et al., 2012).

With respect to the approach system, it should be noted that there is a considerable controversy about what the BAS-related personality trait is. Gray assumed that individuals high in impulsivity are more sensitive to reward signals, and employed the term “impulsivity" for the personality trait reflecting BAS sensitivity. However, several studies emphasize a distinction between impulsivity (which provokes behaviors that are rash and spontaneous) and sensitivity to unconditioned/conditioned rewarding stimuli (for a review see Franken \& Muris, 2006; Poythress \& Hall, 2011). Indeed, Carver and White developed three scales to assess BAS activity: Drive (BAS-DR) items relate to the strong pursuit of appetitive goals, Reward-Responsiveness (BAS-RR) items focus on positive responses to the occurrence of reward, and Fun-Seeking (BAS-FS) items reflect both a tendency to seek out new potentially rewarding experiences and a tendency to act on the spur of the moment. There is now growing experimental evidence indicating that BAS-DR and BAS-RR are associated with reward sensitivity, whereas BAS-FS is more related to rash impulsiveness and sensation seeking (e.g., Smillie \& Jackson, 2006).

Inasmuch as they seem adequate to capture individual differences in reward and punishment responsiveness proposed in Gray's original and revised RST — the most important behavioral and physiological model of personality_, BIS/BAS scales have been linked to other major personality theories such as the Five-Factor Model (FFM; Costa \& McCrae, 1992). In the first study examining relationships between BIS/BAS scales and FFM domains, Smits and Boeck (2006) found that the original BIS-scale was positively related to Neuroticism, Agreeableness, and Conscientiousness, and negatively to Extraversion. With regard to the BAS, all three scales were positively related to Extraversion, but other FFM domains showed specific associations only with certain BAS subscales: BAS-FS was 
positively related to Openness and negatively to Agreeableness and Conscientiousness, while BAS-DR was unrelated to Openness, negatively related to Agreeableness and positively related to Conscientiousness. These data suggested that BAS-FS is preferentially reflecting impulsivity, sensation-seeking, and low constraint, while the other BAS scales tap distinctive —albeit related — constructs. However, this study explored relationships for RST systems only at the FFM domain level, and, remarkably, without considering the BIS-Anxiety and BIS-Fear distinction.

Recently, Keiser and Ross (2011) overcame these limitations by examining the revised BIS-Anxiety and BIS-Fear scales, besides overall BAS, in relation to the domains and facets of the FFM. Neuroticism and Conscientiousness were positive predictors of both BIS-Anxiety and BIS-Fear, and the Agreeableness domain — and its specific facets of Compliance and Modesty- also positively predicted BIS-Anxiety, but not BIS-Fear. Overall BAS was positively predicted by Extraversion and negatively by Agreeableness. Unfortunately, differential relationships between BAS subscales and the FFM were not investigated. This fact is of particular importance in light of the debate about which personality traits exactly underlie BAS activity, and the reported interrelations between the BIS and BAS subscales (e.g., Heym et al., 2008), which highlight the need to control for the effects of each subscale on the others when examining relations with criteria variables.

In view of limitations of previous research, our study was aimed to delineate differences among BIS/BAS subscales from the FFM, both at the domain and facet level, distinguishing BIS-Fear from BIS-Anxiety within the original BIS-scale and parsing the BAS construct into separate BAS-DR, BAS-RR, and BAS-FS. To this end, we first examined the factor structure of the Spanish version of the BIS/BAS scales to check whether the division of the original BIS-scale into two factors was confirmed. Secondly, we explored the relations of each 
BIS/BAS subscale with the facets and domains of the FFM — assessed by the NEO-PI-R — in order to clarify the differential personality patterns underlying the updated RST.

\section{Method}

\subsection{Participants and procedure}

Participants were 329 undergraduates (45\% males) from Universitat Jaume I of Castellón (Spain), with a mean age of 20.23 years $(\mathrm{SD}=2.72)$. All participants provided informed consent, filled the questionnaires anonymously in small group sessions of 20-40 students, and were paid $12 €$ for their participation.

\subsection{Measures}

The BIS/BAS scales (Carver \& White, 1994) consists of 24 items: 7 items designed to assess BIS reactivity, 13 items designed to assess BAS activity through three subscales Drive (BAS-DR; 4 items), Fun-Seeking (BAS-FS; 4 items), and Reward-Responsiveness (BAS-RR; 5 items)—, and 4 filler items. Each item is scored using a 4-point Likert scale from "strongly agree" to "strongly disagree". In a Spanish sample of undergraduates (Caseras, Ávila, \& Torrubia, 2003), $\alpha$ coefficients ranged from 0.65 to 0.82 .

The Sensitivity to Punishment and Sensitivity to Reward Questionnaire (SPSRQ; Torrrubia, Ávila, Moltó, \& Caseras, 2001) is a 48-yes/no questionnaire designed to assess individual differences in Gray's dimensions through two scales: Sensitivity to Punishment (SP; 24 items) and Sensitivity to Reward (SR; 24 items). In the current study, $\alpha$ coefficients were 0.86 for SP and 0.79 for SR.

The Anxiety-Trait Scale (STAI-T) from the State-Trait Anxiety Inventory (Spielberger, Gorsuch, \& Lushene, 1970) is a 20-item measure of anxiety as a general trait that is answered on a four-point Likert scale from "almost never" to "almost always". In the current study, $\alpha$ coefficient was 0.87 . 
The Revised NEO Personality Inventory (NEO-PI-R; Costa \& McCrae, 1992) is a 240item Likert questionnaire, ranging from "strongly disagree" to "strongly agree". It was designed to assess the personality domains of Neuroticism, Extraversion, Openness, Agreeableness, and Conscientiousness. Each domain is composed of six facet scales. In the current study, $\alpha$ coefficients were 0.90 for Neuroticism, 0.88 for Extraversion, 0.87 for Openness, 0.89 for Agreeableness, and 0.91 for Conscientiousness. At the facet level, $\alpha$ coefficients ranged from 0.41 (Excitement-Seeking) to 0.84 (Depression), with an average of 0.69 .

\section{Results and discussion}

An exploratory principal axis factor analysis (EFA) with a direct oblimin rotation was used to test for the factor structure of the Spanish version of BIS/BAS scales. Following previous studies (e.g., Carver \& White, 1994; Dissabandara et al., 2012; Poythress et al., 2008), an oblique rotation was chosen since some of the constructs were predicted to be correlated. Both the Kaiser-Meyer-Olkin's index (0.80) and the Bartlett's test of sphericity, $\mathrm{X}^{2}$ $(190)=1539, p<.0001$, showed the adequacy to conduct a factor analysis on the data.

A set of criteria (Kaiser's eigenvalues $>1$, Cattell's scree test, and parallel analysis) suggested a five-factor solution, accounting for $54.22 \%$ of the variance (eigenvalues $=3.60$, $3.38,1.48,1.36$, and 1.03). Factor loadings of BIS/BAS items after rotation are shown in Table 1. Consistent with Corr and McNaughton's (2008) proposal that the BIS-scale may be separated into fear and anxiety components, three of its items (2, 16 and 22) loaded on a BISFear factor, whereas the remaining four items formed a separate factor tapping anxiety. Importantly, these two factors correspond exactly to those found in previous studies using non-clinical samples (Dissabandara et al., 2012; Heym et al., 2008). BAS-items also loaded 
significantly on their expected components except item 23 of BAS-RR, which showed higher loadings on BAS-DR and BAS-FS factors than on its expected factor.

Internal consistencies of BIS/BAS subscales were acceptable, ranging from .59 for BISFear and BAS-RR to .70 for BIS-Anxiety — with values of .66 for BAS-FS and .69 for BASDR. As expected, the two BIS subscales were positively correlated $(r=.47, p<.0001)$, as were the three BAS subscales ( $r=.34$ between BAS-FS and BAS-DR, $r=.31$ between BASFS and BAS-RR, and $r=.22$ between BAS-DR and BAS-RR, all $p s<.0001)$. Furthermore, BIS-Anxiety was positively related to BAS-RR $(r=.36, p<.0001)$ as in previous studies (e.g., Dissabandara et al., 2012; Heym et al., 2008).

Irrespective of higher scores in BIS-Anxiety (13.76 vs. 12.20), BIS-Fear (8.57 vs. 7.64) and BAS-RR (17.32 vs. 16.50) for women than men (all $p s<.0001)$, the pattern of relationships between BIS/BAS subscales and criteria variables was not significantly different across gender (evaluated against a critical alpha of .001 to correct for multiple comparisons), and so all analyses were performed in a combined data set.

Table 2 shows zero-order correlations between the BIS/BAS scores and STAI-T, SPSRQ, and NEO-PI-R domain and facet scores. Consistent with Gray's model, BIS-Total was positively related to Neuroticism and negatively to Extraversion, and BAS-Total was positively related to both Neuroticism and Extraversion. Furthermore, Conscientiousness was positively related to BIS-Total and Openness to BAS-Total, whereas Agreeableness was positively related to BIS but negatively to BAS, consonant with previous studies (cf. Keiser \& Ross, 2011; Smits \& Boeck, 2006).

Given the existence of associations among the five BIS/BAS subscales, the differential contribution of each subscale in the pattern of relations was examined by computing partial correlations to control for common variance among the other four BIS/BAS subscales (see Table 2). Regarding BIS, both BIS-Anxiety and BIS-Fear were positively associated with 
BIS-related measures (SP and STAI-T) and Neuroticism, supporting McNaughton and Corr's (2004) hypothesis that neuroticism dimension underlies BIS and FFS activity. Remarkably, only BIS-Anxiety was negatively associated with Extraversion, indicating that anxious individuals are Neurotic-Introverts. This result is consistent with Gray's proposal that the anxiety dimension runs from $\mathrm{N}+/ \mathrm{E}-$ to $\mathrm{N}-/ \mathrm{E}+$ quadrants, being the neurotic-introvert individuals the most sensitive to signals of punishment and especially prone to anxiety disorders. In addition, only BIS-Anxiety was negatively related to the Impulsiveness facet of Neuroticism and SR — a scale specifically designed to measure Gray's impulsivity dimension.

In terms of the other NEO-PI-R domains, both Agreeableness and Conscientiousness were more strongly related to BIS-Anxiety than BIS-Fear $(z=3.17$ and $z=3.00$, respectively, $p s<.01)$. After partialling out, BIS-Anxiety — but not BIS-Fear- was positively related to Agreeableness, confirming that this dimension distinguishes between BIS and FFS systems (cf. Keiser \& Ross, 2011), but also to Conscientiousness (specifically, the Order, Dutifulness and Deliberation facets), to which BIS-fear was negatively related. These results further characterize high BIS-Anxiety scorers as agreeable people, as well as methodical, wellorganized, reliable individuals with tendency to think carefully before acting. Our findings are consistent with the hypothetical personality traits that seem to characterize anxious people, and show that BIS-Anxiety and BIS-Fear can be reliably distinguished via FFM Agreeableness and Conscientiousness domains and facets.

Regarding BAS, only BAS-FS was positively related to both Extraversion (all facets except Assertiveness) and Neuroticism (Impulsiveness, Angry Hostility and Vulnerability facets), consistent with the Gray's impulsivity dimension running from N+/E+ to N-/Equadrants. BAS-FS was also significantly related to all facets of Openness $(+)$ and Conscientiousness (-), besides the Straightforwardness and Compliance facets of Agreeableness (-), thus describing high BAS-FS scorers as individuals open to new 
experiences, with somewhat deceitful and aggressive tendencies, and with notably low constraint. This pattern of relationships seems to confirm that BAS-FS captures Gray's impulsivity along with sensation seeking and rash impulsiveness (cf. Franken \& Muris, 2006).

Unlike the BAS-FS, BAS-RR was unrelated to Neuroticism and positively related to all facets of Conscientiousness, as well as to Extraversion (Warmth, Assertiveness, Activity and Positive Emotions facets), suggesting that high BAS-RR scorers are extraverted and determined individuals, with ability to control impulses and to focus on future-oriented planning, and a tendency to experience excitement towards future rewards (cf. Heym et al., 2008). Our results support the idea that BAS-RR assesses BAS aspects of reward-reactivity and reward-expectancy that are conceptually different to the impulsiveness trait and poor behavioral control associated with BAS-FS (cf. Smillie, Jackson, \& Dalgleish, 2006).

In this respect, it should be noted that BAS-DR seems to capture yet another different facet of BAS activity — one related to a competitive rather than cooperative interpersonal style to approach goals. Thus, only this scale was negatively related to all facets of Agreeableness (i.e., high antagonism) while showing significant positive correlations with the Order, Achievement-Striving, and Self-Discipline facets of Conscientiousness, reflecting people's tendency to go all out to get their objectives. Combined with relations to the Assertiveness facet of Extraversion (+), the Angry Hostility facet of Neuroticism (+), and Openness (-), the pattern of relationships suggests that high BAS-DR scorers are dominant, aggressive, closed-minded, and willing to work hard to achieve their goals even putting their own interests above those of others. Although a similar relation between the Agreeableness domain and BAS-DR has been previously reported (cf. Smits \& Boeck, 2006), much more work is required in this area.

\section{Conclusion and limitations}


This study extends Keiser and Ross' (2011) work by examining the domains and facets of the NEO-PI-R in relation to the five subscales within the Carver and White's (1994) BIS/BAS scales: BIS-Anxiety, BIS-Fear, BAS-DR, BAS-FS, and BAS-RR.

Closely paralleling recent work testing the structure of the BIS/BAS scales in non-clinical samples (Dissabandara et al., 2012; Heym et al., 2008), a 5-factor solution was found in our study, with the BIS-scale separated into four-item BIS-Anxiety and three-item BIS-Fear factors, besides the three BAS factors. In addition to supporting the hypothesized latent structure of BIS/BAS scales, this study is the first to investigate the specific higher- and lower-order FFM personality traits related to each of these five scales, allowing us to identify the distinct personality configurations that are related to individual differences in sensitivity to punishment and reward stimuli.

Taken as a whole, our findings evidence the existence of relevant divergences in BIS/BAS subscales via FFM facets and domains, especially related to both Agreeableness and Conscientiousness. On the one hand, these domains support the distinction between fear and anxiety into the original BIS-scale, being BIS-Anxiety positively related to both Agreeableness and Conscientiousness and BIS-Fear unrelated to the former and negatively related to the latter. On the other, notably distinct patterns of relationships of the BAS subscales with Agreeableness and Conscientiousness question the validity of focusing uniquely on a BAS total score (for example, Keiser \& Ross, 2011) that may mask opposing associations at the subscale level (cf. Heym et al., 2008). In our study, the relationship between overall BAS and low Agreeableness is mainly explained by BAS-DR, whereas BAS' lack of relationship with Conscientiousness seems to result from a suppressor effect between negative relations to BAS-FS and positive relations to BAS-RR and BAS-DR. Future studies should further clarify the personality constructs that underlie the different components of BAS activation. 
Our current findings, however, were limited by exclusive reliance on self-report questionnaires. It would be beneficial for future research to incorporate laboratory tasks to identify divergences in behavioral performance among the BIS, FFS, and BAS subsystems as reported here. In addition, despite positive findings, our sample only consisted of undergraduates and, therefore, our results ought to be replicated in other populations, and specifically in clinical samples for the sake of generalizability. Finally, the findings of this study have methodological implications for other scales designed to measure the RST constructs, such as the SPSRQ, and suggest a re-evaluation of their items in the light of the revised RST.

\section{References}

Beck,I., Smits, D.J.M., Claes, L., Vandereycken, W., \& Bijttebier, P. (2009). Psychometric evaluation of the Behavioral Inhibition/Behavioral Activation System scales and the Sensitivity to Punishment and Sensitivity to Reward Questionnaire in a sample of eating disordered patients. Personality and Individual Differences, 47, 407-412.

Carver, C.S., \& White, T.L. (1994). Behavioral inhibition, behavioral activation, and affective responses to impending reward and punishment: The BIS/BAS scales. Journal of Personality and Social Psychology, 67, 319-333.

Caseras, X., Ávila, C., \& Torrubia, R. (2003). The measurement of individual differences in behavioural inhibition and behavioural activation systems: A comparison of personality scales. Personality and Individual Differences, 34, 999-1013.

Corr, P.J. (2004). Reinforcement sensitivity theory and personality. Neuroscience and Biobehavioral Reviews, 28, 317-332.

Corr, P.J. (2008). The Reinforcement Sensitivity Theory of Personality. Cambridge: Cambridge University Press. 
Corr, P.J., \& McNaughton, N. (2008). Reinforcement sensitivity theory and personality. In P.J. Corr (Ed.), The reinforcement sensitivity theory of personality (pp. 155-187). Cambridge: Cambridge University Press.

Costa, P.T., \& McCrae, R.R. (1992). The NEO-PI-R professional manual. Odessa, FL: Psychological Assessment Resources. Spanish version: Cordero, A., Pamos, A., \& Seisdedos, N. (1999). Madrid: TEA Ediciones.

Dissabandara, L.O., Loxton, N.J., Dias, S.R., Daglish, M., \& Stadlin, A. (2012). Testing the fear and anxiety distinction in the BIS/BAS scales in community and heroin-dependent samples. Personality and Individual Differences, 52, 888-892.

Franken, I.H.A., \& Muris, P. (2006). Gray's impulsivity dimension: A distinction between reward sensitivity and rash impulsiveness. Personality and Individual Differences, 40, $1337-1347$.

Gray, J.A. (1970). The psychophysiological basis of introversion-extraversion. Behaviour Research and Therapy, 8, 249-266.

Gray, J.A. (1981). A critique of Eysenck's theory of personality. In H.J. Eysenck (Ed.), A model of personality (pp. 246-276). Berlin: Springer

Gray, J.A. (1982). The neuropsychology of anxiety: An inquiry into the functions of the septal-hippocampal system. Oxford: Oxford University Press.

Gray, J.A. (1987). The psychology of fear and stress. London: Cambridge University Press.

Gray, J.A. (1991). Neural systems, emotion and psychopathology. In J. Madden (Ed.), Neurobiology of learning, emotion and affect (pp. 273-306). New York: Raven Press.

Gray, J.A., \& McNaughton, N. (2000). The neuropsychology of anxiety: An inquiry into the functions of the septo-hippocampal system. Oxford: Oxford University Press. 
Heym, N., Ferguson, E., \& Lawrence, C. (2008). An evaluation of the relationship between Gray's revised RST and Eysenck's PEN: Distinguishing BIS and FFS in Carver and White’s BIS/BAS scales. Personality and Individual Differences, 45, 709-715.

Heym, N., \& Lawrence, C. (2010). The role of Gray's revised RST in the P-psychopathy continuum: The relationships of Psychoticism with a lack of fear and anxiety, and increased impulsivity. Personality and Individual Differences, 49, 864-879.

Johnson, S.L., Turner, R.J., \& Iwata, N. (2003). BIS/BAS levels and psychiatric disorder: an epidemiological study. Journal of Psychopathology and Behavioral Assessment, 25, 2536.

Keiser, H.N., \& Ross, S.R. (2011). Carver and Whites’ BIS/FFS/BAS scales and domains and facets of the Five Factor Model of personality. Personality and Individual Differences, $51,39-44$.

McNaughton, N., \& Corr, P.J. (2004). A two-dimensional neuropsychology of defense: Fear/anxiety and defensive distance. Neuroscience and Biobehavioral Reviews, 28, 285305.

Poythress, N.G., \& Hall, J.R. (2011). Psychopathy and impulsivity reconsidered. Aggression and Violent Behavior, 16, 120-134.

Poythress, N.G., Skeem, J.L., Weir, J., Lilienfeld, S.O., Douglas, K.S., Edens, J.F., \& Kennealy, P.J. (2008). Psychometric properties of Carver and White's (1994) BIS/BAS scales in a large sample of offenders. Personality and Individual Differences, 45, 732737.

Smillie, L., \& Jackson, C. (2006). Functional impulsivity and Reinforcement Sensitivity Theory. Journal of Personality, 74, 48-83. 
Smillie, L.D., Jackson, C.J., \& Dalgleish, L.I. (2006). Conceptual distinctions among Carver and White's (1994) BAS scales: A reward-reactivity versus trait impulsivity perspective. Personality and Individual Differences, 40, 1039-1050.

Smillie, L., Pickering, A., \& Jackson, C. (2006). The new Reinforcement Sensitivity Theory: Implications for personality measurement. Personality and Social Psychology Review, $10,320-335$.

Smits, D.J.M., \& Boeck, P.D. (2006). From BIS/BAS to the big five. European Journal of Personality, 20, 255-270.

Spielberger, C.D., Gorsuch, R.L., \& Lushene, R.E. (1970). Manual for the State-Trait Anxiety Inventory. Palo Alto, CA: Consulting Psychologists Press. Spanish version: Seisdedos, N. (1982). Madrid: TEA ediciones.

Torrrubia, R., Ávila, C., Moltó, J., \& Caseras, X. (2001). The Sensitivity to Punishment and Sensitivity to Reward Questionnaire (SPSRQ) as a measure of Gray's anxiety and impulsivity dimensions. Personality and Individual Differences, 31, 837-862. 


\section{Table Captions}

Table 1.

Factor loadings for BIS/BAS items

\section{Table 2.}

Bivariate (and partial) correlations of BIS and BAS total and subscale scores with STAI-T, SPSRQ, and NEO-PI-R domain and facet scores 
Table 1

Factor loadings for BIS/BAS items

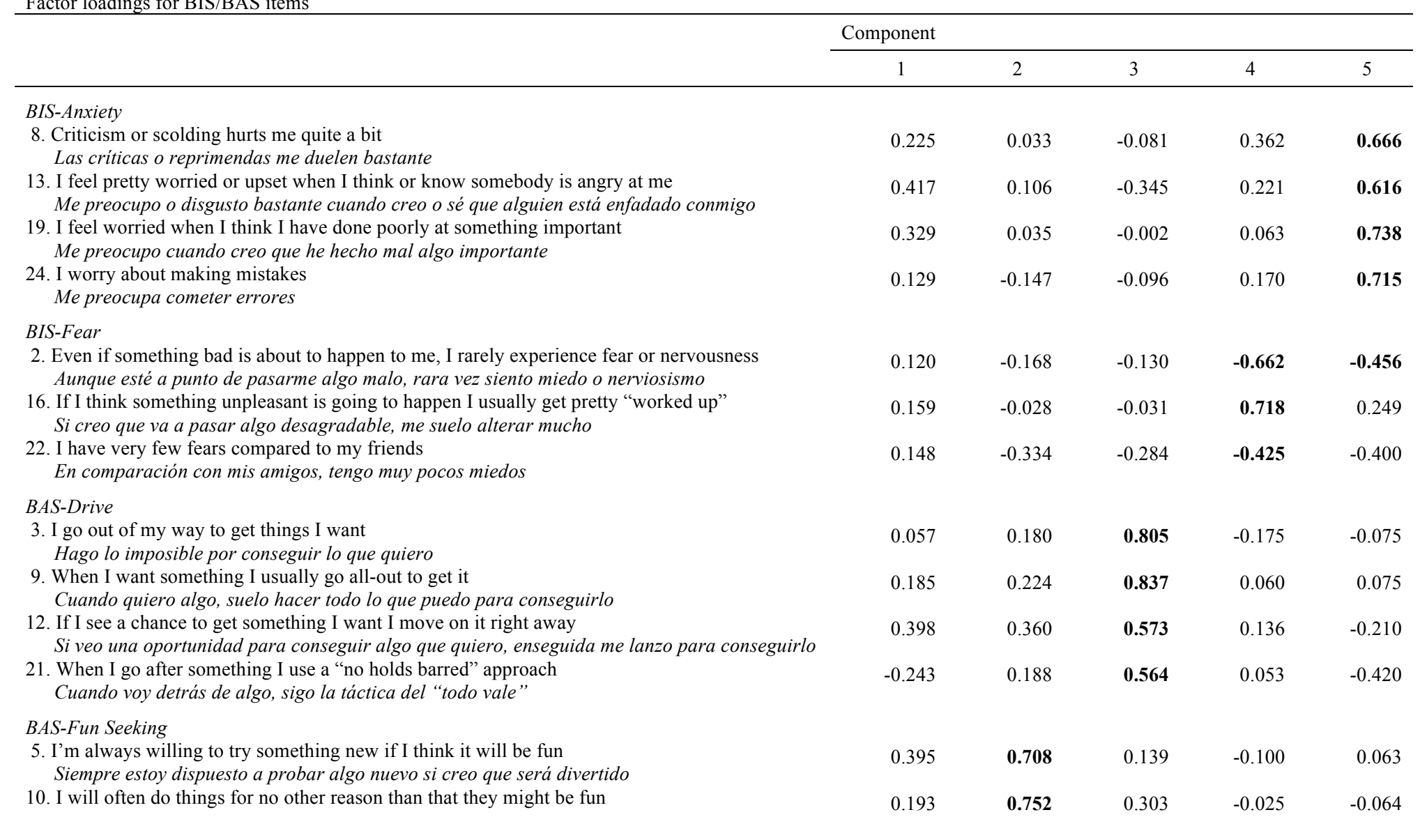


A menudo soy capaz de hacer cosas sólo porque puedan ser divertidas 15. I often act on the spur of the moment

A menudo actúo sin pensar

20. I crave excitement and new sensations

Ansio experimentar emociones y nuevas sensaciones

BAS-Reward Responsiveness

4. When I'm doing well at something I love to keep at it

Cuando hago algo bien, me gusta continuar con ello

7. When I get something I want, I feel excited and energized

Cuando consigo lo que quiero, me siento entusiasmado y con energía

14. When I see an opportunity for something I like I get excited right away

Cuando veo una oportunidad para conseguir algo que me gusta, me entusiasmo enseguida

18. When good things happen to me, it affects me strongly

Cuando me pasa algo bueno, me afecta profundamente

23 . It would excite me to win a contest

Me entusiasmaría ganar un concurso

\begin{tabular}{lllll}
-0.066 & $\mathbf{0 . 5 2 2}$ & 0.158 & 0.384 & -0.246 \\
0.029 & $\mathbf{0 . 7 5 4}$ & 0.171 & -0.022 & -0.048 \\
& & & & \\
$\mathbf{0 . 7 2 6}$ & 0.051 & 0.016 & -0.111 & 0.270 \\
$\mathbf{0 . 7 7 6}$ & 0.194 & 0.142 & -0.017 & 0.300 \\
$\mathbf{0 . 5 9 9}$ & 0.413 & 0.211 & 0.368 & 0.119 \\
$\mathbf{0 . 6 0 9}$ & 0.048 & -0.051 & 0.275 & 0.164 \\
0.147 & 0.353 & 0.330 & 0.174 & -0.010 \\
\hline 18.00 & & & & \\
\hline
\end{tabular}

|

18.00

16.92

7.40

6.77

5.13

Note. Loadings $>|0.42|$ are in bold

Spanish version of the Carver \& White's (1994) BIS/BAS items are italicized. 


\begin{tabular}{|c|c|c|c|c|c|c|c|}
\hline & BIS-Total & BIS-Anxiety & BIS-Fear & BAS-Total & BAS-DR & BAS-FS & BAS-RR \\
\hline STAI-T & $.52 * * *$ & $.44 * * *(.34 * * *)$ & $.43 * * *(.32 * * *)$ & .07 & $.00(.12 *)$ & $.04(.09)$ & $.10(-.11)$ \\
\hline \multicolumn{8}{|l|}{ SPSRQ } \\
\hline SP & $.52 * * *$ & $.47 * * *(.36 * * *)$ & $.43 * * *(.22 * * *)$ & $-.20 * * *$ & $-.19 * * *(-.00)$ & $-.27 * * *(-.24 * * *)$ & $.05(-.06)$ \\
\hline$S R$ & $-.17 * *$ & $-.17 * *\left(-.16^{* *}\right)$ & $-.11(.06)$ & $.52 * * *$ & $.51 * * *(.40 * * *)$ & $.40 * * *(.27 * * *)$ & $.20 * * *(.08)$ \\
\hline \multicolumn{8}{|l|}{$N E O-P I-R$} \\
\hline Neuroticism & $.59 * * *$ & $.48 * * *(.33 * * *)$ & $.53 * * *(.44 * * *)$ & $.13^{*}$ & $-.00_{\mathrm{d}}(.12 *)$ & $.11\left(.19^{* * *}\right)$ & $.18 * * *{ }_{d}(-.08)$ \\
\hline Anxiety & $.64 * * *$ & $.47 * * * *_{a}(.24 * * *)$ & $.63 * * *_{a}(.54 * * *)$ & .05 & $-.05_{\mathrm{d}}(.09)$ & $-.03_{\mathrm{c}}(.03)$ & $.21 * * *_{\mathrm{cd}}(.03)$ \\
\hline Angry Hostility & $.16^{* *}$ & $.14 * *(.13 *)$ & $.14^{* *}\left(.16^{* *}\right)$ & $.22 * * *$ & $.18 * * *(.17 * *)$ & $.25 * * *_{\mathrm{c}}(.25 * * *)$ & $.04_{\mathrm{c}}\left(.15^{* *}\right)$ \\
\hline Depression & $.52 * * *$ & $.49 * * *(.39 * * *)$ & $.39 * * *(.22 * * *)$ & -.00 & $-.08_{\mathrm{d}}(.06)$ & $-.02(.03)$ & $.10_{\mathrm{d}}(-.11)$ \\
\hline Self-Consciousness & $.47 * * *$ & $.43 * * *(.31 * * *)$ & $.38 * * *(.21 * * *)$ & -.11 & $-.16 * *_{d}(-.02)$ & $-.14 * *_{c}(-.08)$ & $.07_{\mathrm{cd}}(-.06)$ \\
\hline Impulsiveness & .09 & $-.01_{\mathrm{a}}\left(-.15^{* *}\right)$ & $.17 * *{ }_{a}(.31 * * *)$ & $.39 * * *$ & $.22 * * *{ }_{b}(.10)$ & $.43 * * * b c(.42 * * *)$ & $.20 * * * *_{c}(.05)$ \\
\hline Vulnerability & $.59 * * *$ & $.48 * * *(.30 * * *)$ & $.54 * * *(.44 * * *)$ & .09 & $-.04_{d}(.08)$ & $.07\left(.15^{* *}\right)$ & $.18 * * *{ }_{d}(-.05)$ \\
\hline Extraversion & $-.13^{*}$ & $-.12 *(-.20 * * *)$ & $-.09(.04)$ & $.45^{* * *}$ & $.24 * * * *_{b}(.04)$ & $.45 * * *{ }_{b c}(.37 * * *)$ & $.27 * * *_{\mathrm{c}}(.21 * * *)$ \\
\hline Warmth & .10 & $.11(.03)$ & $.05(.01)$ & $.16^{* *}$ & $-.00_{\mathrm{d}}(-.07)$ & $.15^{* *}\left(.12^{*}\right)$ & $.21 * * *_{d}\left(.15^{* *}\right)$ \\
\hline Gregariousness & .11 & $.08(-.02)$ & $.12 *\left(.15^{* *}\right)$ & $.27 * * *$ & $.13 *(.05)$ & $.25 * * *(.21 * * *)$ & $.21 * * *(.10)$ \\
\hline Assertiveness & $-.31 * * *$ & $-.30 * * *(-.24 * * *)$ & $-.23 * * *(-.07)$ & $.28 * * *$ & $.33 * * *{ }_{d}(.22 * * *)$ & $.18 * * *(.05)$ & $.09_{\mathrm{d}}\left(.13^{*}\right)$ \\
\hline Activity & $-.12 *$ & $-.11\left(-.16^{* *}\right)$ & $-.09(.03)$ & $.39 * * *$ & $.19 * * *_{b}(-.00)$ & $.43 * * *{ }_{b c}(.37 * * *)$ & $.22 * * *_{c}\left(.16^{* *}\right)$ \\
\hline Excitement-Seeking & $-.23 * * *$ & $-.21 * * *(-.22 * * *)$ & $-.17 * *(.02)$ & $.47 * * *$ & $.29 * * *_{b}(.08)$ & $.56^{* * *}{ }_{b c}(.51 * * *)$ & $.15 * *_{\mathrm{c}}(.06)$ \\
\hline Positive Emotions & -.10 & $-.09\left(-.16^{* *}\right)$ & $-.07(-.00)$ & $.26 * * *$ & $.06_{\mathrm{b}}(-.11)$ & $.29 * * * *_{b}(.24 * * *)$ & $.22 * * *(.21 * * *)$ \\
\hline Openness & .03 & $.07(.01)$ & $-.02(-.02)$ & $.20 * * *$ & $-.03_{\mathrm{bd}}\left(-.16^{* *}\right)$ & $.31 * * *{ }_{b}(.31 * * *)$ & $.16^{* *}{ }_{\mathrm{d}}(.09)$ \\
\hline Fantasy & .09 & $.08(-.03)$ & $.08(.08)$ & $.16^{* *}$ & $-.04_{\mathrm{bd}}(-.13 *)$ & $.23 * * *{ }_{b}(.23 * * *)$ & $.17 * *_{\mathrm{d}}(.11)$ \\
\hline Aesthetics & .10 & $.12 *(.06)$ & $.04(-.02)$ & .05 & $-.10_{\mathrm{bd}}(-.14 * *)$ & $.10_{\mathrm{b}}(.11)$ & $.11_{\mathrm{d}}(.07)$ \\
\hline Feelings & -.00 & $.01(-.05)$ & $-.02(.04)$ & $.36^{* * *}$ & $.15 * *_{b}(.00)$ & $.40 * * *{ }_{b c}(.33 * * *)$ & $.24 * * *_{\mathrm{c}}(.14 * *)$ \\
\hline Actions & -.07 & $-.02(.01)$ & $-.10(-.06)$ & $.19^{* * *}$ & $.04_{b}(-.08)$ & $.33 * * *{ }_{b c}(.33 * * *)$ & $.03_{\mathrm{c}}(-.05)$ \\
\hline Ideas & -.10 & $-.06(-.03)$ & $-.12 *(-.10)$ & .06 & $-.02(-.09)$ & $.12 *(.12 *)$ & $.02(.03)$ \\
\hline Values & $.13^{*}$ & $.14 * *(.08)$ & $.07(.01)$ & .05 & $-.12 *_{b d}\left(-.15^{* *}\right)$ & $.13 *_{b}\left(.16^{* *}\right)$ & $.10_{\mathrm{d}}(.04)$ \\
\hline Agreeableness & $.36^{* * *}$ & $.39 * * * *_{a}(.29 * * *)$ & $.22 * * * *_{a}(-.01)$ & $-.29 * * *$ & $-.44 * * *{ }_{b d}(-.37 * * *)$ & $-.19 * * *{ }_{b c}(-.09)$ & $.04_{\mathrm{cd}}(.04)$ \\
\hline Trust & .04 & $.08(.05)$ & $-.02(-.08)$ & -.05 & $-.17 * *$ bd $(-.19 * * *)$ & $.01_{\mathrm{b}}(.03)$ & $.07 \mathrm{~d}(.08)$ \\
\hline
\end{tabular}




\begin{tabular}{|c|c|c|c|c|c|c|c|}
\hline Straightforwardness & $.35^{* * *}$ & $.32 * * *(.20 * * *)$ & $.27 * * *(.08)$ & $-.36 * * *$ & $-.46^{* * *} \mathrm{bd}\left(-.36^{* * *}\right)$ & $-.28 * * * b c\left(-.16^{* *}\right)$ & $-.02_{\mathrm{cd}}(.02)$ \\
\hline Altruism & $.22 * * *$ & $.24 * * *\left(.16^{* *}\right)$ & $.13 *(-.01)$ & -.11 & $-.22 * * * b d(-.18 * * *)$ & $-.07_{\mathrm{b}}(-.02)$ & $.08_{\mathrm{d}}(.05)$ \\
\hline Compliance & $.24 * * *$ & $.25 * * *(.18 * * *)$ & $.16 * *(-.02)$ & $-.31 * * *$ & $-.36 * * *{ }_{d}(-.26 * * *)$ & $-.26 * * *{ }_{c}(-.17 * *)$ & $-.03_{\mathrm{cd}}(.01)$ \\
\hline Modesty & $.39 * * *$ & $.41 * * * *_{\mathrm{a}}(.35 * * *)$ & $.24 * * *_{a}(.00)$ & $-.30 * * *$ & $-.41 * * * b \mathrm{bd}(-.31 * * *)$ & $-.20 * * *_{b c}(-.08)$ & $-.02_{\text {cd }}(-.07)$ \\
\hline Tender-Mindedness & $.28 * * *$ & $.33 * * *{ }_{a}(.24 * * *)$ & $.14 * *_{a}(-.02)$ & -.02 & $-.21 * * *$ bd $(-.21 * * *)$ & $.04_{b}(.09)$ & $.15 * *_{d}(.07)$ \\
\hline Conscientiousness & $.14 * *$ & $.20 * * *{ }_{a}(.19 * * *)$ & $.03_{\mathrm{a}}\left(-.15^{* *}\right)$ & -.08 & $.00_{\mathrm{b}}\left(.12^{*}\right)$ & $-.33 * * *{ }_{b c}(-.43 * * *)$ & $.16 * *_{c}(.22 * * *)$ \\
\hline Competence & .03 & $.08(.07)$ & $-.03(-.12 *)$ & .00 & $.05_{\mathrm{b}}(.10)$ & $-.20 * * * b c(-.29 * * *)$ & $.16^{* *} *_{\mathrm{c}}(.20 * * *)$ \\
\hline Order & $.20 * * *$ & $.23 * * *(.19 * * *)$ & $.10(-.04)$ & -.02 & $.04_{\mathrm{b}}\left(.14^{* *}\right)$ & $-.22 * * * b c(-.30 * * *)$ & $.16^{* *} *_{c}(.14 * *)$ \\
\hline Dutifulness & $.16^{* *}$ & $.25 * * *{ }_{\mathrm{a}}(.24 * * *)$ & $.00_{\mathrm{a}}(-.19 * * *)$ & -.11 & $-.11_{d}(-.03)$ & $-.25 * * * *_{\mathrm{c}}(-.31 * * *)$ & $.14 * *_{\mathrm{cd}}(.17 * *)$ \\
\hline Achievement-Striving & .11 & $.13 *(.09)$ & $.06(-.01)$ & $.15^{* *}$ & $.18 * * * *_{\mathrm{b}}(.21 * * *)$ & $-.06_{\mathrm{bc}}\left(-.19^{* * *}\right)$ & $.22 * * *_{\mathrm{c}}(.18 * * *)$ \\
\hline Self-Discipline & -.06 & $.01(.06)$ & $-.12 *(-.17 * *)$ & -.00 & $.08_{\mathrm{b}}(.11)$ & $-.16 * * b c(-.25 * * *)$ & $.08_{\mathrm{c}}\left(.13^{*}\right)$ \\
\hline Deliberation & $.17 * *$ & $.20 * * *(.19 * * *)$ & $.09(-.12 *)$ & $-.33 * * *$ & $-.19 * * * *_{b d}(-.02)$ & $-.52 * * * b c(-.54 * * *)$ & $.02_{\mathrm{cd}}\left(.16^{* *}\right)$ \\
\hline
\end{tabular}

Note. Within each BIS or BAS component, correlations with the same subscript are significantly different from one another $(p<.01)$, tested via Steiger's test for related samples. $* p<.05, * * p<.01, * * * p<.001$. 